\title{
Simulating inadequate dialysis and its correction using an individualized patient-derived nomogram
}

\author{
Colin T. White
}

Received: 13 July 2009 / Accepted: 13 July 2009 /Published online: 31 July 2009

(C) IPNA 2009

\begin{abstract}
Optimization of the peritoneal dialysis prescription is dependent on proper characterization of the peritoneal membrane, as obtained by the peritoneal equilibration test (PET) or similar procedure. For any individual, certain predictions can be made to allow for decisions as to number of cycles, bag strength, and other options in order to maximize both small-solute clearance and ultrafiltration. In this paper, designed to address questions around correcting nonadherence to a prescribed peritoneal dialysis (PD) prescription, Lee et al. remind us that by using modeling programs, a series of theoretical prescriptions can be generated for each patient based on changes in cycle number or bag strength. From a selection of these prescriptions and using the current cycler technology that allows for downloading recent patient run data, and uploading new prescriptions, they demonstrate that one can correct for (scripted) nonadherent dialysis in relation to small-solute clearance. Currently, PD programs should be capable of making use of concepts from this study, as well as the ability to provide prescriptive changes via multiple preprogrammed memory cards or over modem/Internet, to provide patients with individually modeled and optimized options to correct certain forms of inadequate dialysis, for example, missed cycles or hours due to power failures.
\end{abstract}

Keywords Automated peritoneal dialysis - Optimization . PET $\cdot$ Nonadherence $\cdot$ Small-solute clearance .

Peritoneal dialysis cycler

\section{T. White $(\bowtie)$}

Division of Nephrology, BC Children's Hospital,

University of British Columbia,

4480 Oak Street, ACB K4-151,

V6H 3V4 Vancouver, BC, Canada

e-mail: cwhite@cw.bc.ca

\section{Introduction}

In the paper by Lee et al. [1], the authors make use of data from peritoneal equilibration tests (PET) from a cohort of children and young adults on automated peritoneal dialysis (APD) in order to address the issue of nonadherence to the prescribed dialysis regimen. Whereas nonadherence is clearly the main thrust of paper, the concepts from this study can be extended to circumstances where for any reason one might have a run of inadequate dialysis nights, and therefore, other important lessons can be taken from this work.

The first lesson relates to the use of the PET itself. What Lee and his colleagues highlight for us is that there is a significant amount of information available to the clinician from a tool such as the PET, which allows us to characterize the type of "dialyzer membrane" of the individual peritoneal dialysis (PD) patient both in adults [2] and children [3]. Most commonly, this data is used to derive an optimal dialysis prescription, aiming to maximize one or both ultrafiltration (UF) and small-molecule clearance (Kt/V) while minimizing time and/or effort on the part of the family. But to use a hemodialysis concept as an analogy, Lee et al. have extended the predictive power of their PD modeling software (PD Adequest ${ }^{\circledR} 2.0$ in this case [4]) to produce the PD membrane equivalent of the hemodialysis (HD) dialyzer KoA curve. Whereas in HD one chooses to vary the blood or dialysate flow rates to achieve particular clearances of a given molecule for a given dialyzer, Lee et al. [1] model a variety of PD conditions, cycle number, and bag strength in their study and then use these results to predict the clearance of small molecules that would be expected for those given parameters and that individual's kidney or peritoneal membrane. With this series of theoretical dialysis runs in hand and the presumption that 
deficient or nonadherent dialysis nights that are "replaced" with one or more "corrective nights" are beneficial, the authors use a limited set of these patient-derived prescriptions to improve the $\mathrm{Kt} / \mathrm{V}$ delivered on nights following the periods of nonadherence to the scripted routine. The novel aspect of this work is that unlike the majority of such corrective prescription changes that are made based on general principles applicable to all patients on any given modality or with particular membrane characteristics, Lee and colleagues [1] use the individual's own PET modeling data to choose the best available alternate or enhanced prescription to: (a) achieve the required $\mathrm{Kt} / \mathrm{V}$ to balance that lost due to prior nonadherence, (b) do the corrections as the month progresses, that is, not waiting till the monthly clinic visit.

The second lesson, while not directly related to the aims of this study, remains an important one nonetheless, namely, that PD in 2009 clearly remains behind HD when it comes to providing real-time, individually optimized dialysis. In 2009, the world of HD provides for online ionic dialysance and hematocrit monitoring, biofeedback controls for temperature control, and systems and algorithms that allow for a variety of ramping strategies for fluid, sodium, and other electrolytes. We can perform online generation and regeneration of ultrapure dialysate solutions that allow for safe hemodiafiltration, can choose from a myriad of state-of-the art dialysis filters and membranes, and program complex patient prescriptions into memory cards for any individual patient and simply insert each into whatever machine is at their station for that run. All of these tools are aimed at achieving a patient-centered, focused, and optimal HD run. Unfortunately the options for such individual therapy in PD are much more limited. Diaz-Buxo has recently outlined many of the functional, mechanical, safety and information technology features required in an ideal PD cycler; and lists as well the functions of many of the current machine models which match some but not all of these ideals, Tables 15.1 - 15.3 [5]. Perhaps Ronco et al. [6] have best outlined the eventual goals for "PD of the future" where they describe the utility of the new dialysate biocompatible solutions including utility of nonlactate solutions [7], amino acid solutions for improving nutrition [8], and the potential to target both osmotic strength and glucose minimization $[9,10]$ while monitoring and maintaining both UF volumes, minimizing intraperitoneal pressures and even providing real time small solute clearance through the use of state of the art biosensors. The possibility for eventual on-line production of these fluids while tantalizingly close, and described in limited cases and using complex regeneration procedures [11, 12], currently remains in the future for routine home based PD.

But what Lee's study [1] demonstrates is that even before the newer technology is brought to bear we could make better use of what is currently available by creating their PD "KoA curves" for each of our patients. With this information in hand we would be able to send families home with sets of labeled and pre-programmed USB or memory cards with specific programs individually designed to achieve certain goals, e.g. increased UF, higher $\mathrm{Kt} / \mathrm{V}$, phosphate removal or perhaps minimal glucose loads. Patients would be able to decide on a nightly basis which prescription was required and swap cards as needed. Or if this is not locally feasible, then the centre could either attempt to upload such a program at times where it was required, or at the very least the information could be kept close at hand so that the dialysis team might make individually targeted suggestions by phone, or during a clinic visit when made aware of 'missed' or lost nights or hours of dialysis.

The paper by Lee et al. [1] does have a number of limitations, including the very nature of the simulation wherein they chose to use their most dedicated patients to model nonadherent ones, and where the dialysis nonadherence was scripted and ordered by the nephrologist to ensure the patients were not put at risk. The authors also freely admit that this study does not demonstrate that this approach would allow for correction of either vastly nonadherent patients nor would it adequately address fluid overload as opposed to inadequate delivery of $\mathrm{Kt} / \mathrm{V}$. As well, the recent paper by Bargman clearly demonstrates the lack of evidence to support improvements in small solute clearances as being sufficient to improve mortality in PD patients [13], perhaps calling into question the authors' decision to choose an averaged $\mathrm{Kt} / \mathrm{V}$ as their outcome of interest. Finally, the issue of nonadherence in the PD population goes far beyond the peritoneal dialysis prescription itself, e.g. fluid abuse, medication nonadherence etc, and clearly this paper does not address these issues.

While keeping these points in mind, Lee et al. [1] should still be congratulated for thinking outside the current PD box. Their paper has reminded us that by more fully using information gathered from the PET and simple modeling programs such as PD Adequest ${ }^{\circledR} 2.0$ [4] individualization of the PD script can, and should, enable more than simple characterization of the individual's peritoneal membrane; and that optimization and evaluation of at least small solute clearance may not be something that needs to wait for the monthly blood work or clinic review.

Eventually one would hope for a PD machine/software system that would not only be programmable with an individual prescription modeled from the PET results to deliver an adequate small molecule clearance and fluid removal - but would do so by making its own adjustments in dialysate composition (minimizing glucose exposure, utilizing 'biocompatible' solutions etc), dwell volumes, concentrations, cycle length etc. In other words it would deliver a dialysis treatment based on patient specific 
characteristics, targets, current flow and catheter characteristics, and be able to re-evaluate these goals on a run-to-run or perhaps even cycle-by-cycle basis, all while minimizing the physical and psychosocial impact of the patient's renal failure on them and their family.

\section{References}

1. Lee AJ, Kho K, Chia KS, Oi TL, Yap C, Foong PP, Lau YW, Lim LK, Aragon E, Liew CW, Yap HK (2009) Simulating inadequate dialysis and its correction using an individualized patient-derived nomogram. Pediatr Nephrol doi:10.1007/s00467-009-1241-7

2. Twardowski ZJ, Nolph KD, Khanna R, Prowant B, Ryan LP, Moore HL, Nielsen MP (1986) Peritoneal equilibration test. Perit Dial Bull 7:138-147

3. Warady BA, Alexander SR, Hossli S, Vonesh E, Geary D, Watkins S, Salusky IB, Kohaut EC (1996) Peritoneal membrane transport function in children receiving long term dialysis. J Am Soc Nephrol 7:2385-2391

4. Vonesh EF, Story KO, O’Neill PD (1999) Adequest International Study Group: A multinational clinical validation study of PD Adequest 2.0. Perit Dial Int 19:556-571

5. Diaz-Buxo JA (2008) Peritoneal dialysis cyclers and other mechanical devices. In: Nissen A, Fine R (eds) Handbook of Dialysis Therapy, 4th edn. Saunders, Elsevier, Philadelphia, pp 248-260

6. Ronco C, Amerling R, Dell'Aquila R, Rodighiero MP, Di Loreto P (2006) Evolution of technology for automated peritoneal dialysis, peritoneal dialysis. In: Ronco C, Della'Acquila R, Rodighiero MP (eds) A clinical update, vol 150. Karger, Basal, pp 291-309

7. Vande Walle J, Raes A, Castillo D, Lutz-Dettinger N, Dejaegher A (1997) Advantages of HCO3 solution with low sodium concentration over standard lactate solutions for acute peritoneal dialysis. Adv Perit Dial 13:179-182

8. Canepa A, Perfumo F, Carrea A, Verrina E, Menoni S, Trivelli A, Gusmano R (1996) Long-term effects of amino acid solutions in children on automated peritoneal dialysis. J Am Soc Nephrol 7:1441 (abstract)

9. Van Biesen W, Boer W, De Greve B, Dequidt C, Vijt D, Faict D, Lameire N (2004) A randomized clinical trial with $0.6 \%$ amino acid $/ 1.4 \%$ glycerol peritoneal dialysis solution. Perit Dial Int $24: 222-230$

10. Heaton A, Ward MK, Johnston DG, Alberti KG, Kerr DN (1986) Evaluation of glycerol as an osmotic agent for continuous ambulatory peritoneal dialysis in end-stage renal failure. Clin Sci 70:23-29

11. Brunkhorst R, Fromm S, Wrenger E, Berke A, Petersen R, Riede G, Westphale J, Zamore E, Ledebo I (1998) Automated peritoneal dialysis with "online"-prepared bicarbonate-buffered dialysate: technique and first clinical experiences. Nephrol Dial Transplant 13:3189-3192

12. Dell'Aquila R, Rodighiero MP, Spano M, Di Loreto P, Ocampo Kohn C, Cruz D, Polanco N, Kuang D, Corradi V, De Cal M, Ronco C (2007) Advances in the technology of automated, tidal and continuous flow peritoneal dialysis. Perit Dial Int 27(Suppl 2): S130-S137

13. Bargman JM (2007) New technologies in peritoneal dialysis. Clin J Am Soc Nephrol 2:576-580 